\title{
CLINICAL ACCURACY OF A COMPUTER-GENERATED SURGICAL GUIDE TEMPLATE IN SANDWICH OSTEOTOMY FOR POSTERIOR EDENTULOUS MANDIBLE
}

\author{
Mohamed Farid Shehab*
}

\begin{abstract}
Background: The study was conducted to evaluate the accuracy of a novel design computergenerated surgical guide template (SGT) using rapid prototyping to guide the osteotomy cuts in sandwich osteotomy technique according to the pre-planned position to prevent injury to the inferior alveolar nerve.

Methods: Eight partially edentulous patients showing atrophy in the posterior mandibular ridge were included. A $S G T$ was designed according to each case using a 3D modeling software to guide the bony osteotomy cuts during the surgical procedure. Preoperative, immediate post-operative and after 4 months CBCT was done for all patients. Dental implants were installed at the grafted sites after 4 months.
\end{abstract}

Results: Linear measurements were taken from the pre and post-operative CBCT. No statistically significant difference was found between the pre and post-operative measurements $(P \leq 0.05)$.

Conclusion: The computer generated SGT provided enhanced visualization, better treatment planning, predictable results and a less technique sensitive procedure.

KEY WORDS: Atrophied posterior mandible, Sandwich osteotomy technique, Computergenerated surgical guide templates, Rapid prototyping

\section{INTRODUCTION}

Alveolar ridge resorption is frequently observed after tooth extraction with substantial reduction of the original alveolar bone height and width ${ }^{1}$. Alveolar ridge atrophy may cause prosthetic problems for the fabrication of conventional or implant- supported prosthesis and surgical problems presenting a difficult clinical situation for placing and positioning of endosseous implants.

Rehabilitation of the partially edentulous posterior mandible with removable dentures can be unsatisfactory for patients and may accelerate bone

* Lecturer, Oral and Maxillofacial Surgery Department, Faculty of Oral and Dental Medicine, Cairo University, Egypt 
turn over in the mandible ${ }^{2,3}$. An implant-supported prosthesis could be the ideal option. There are many techniques used in attempt to overcome decreased alveolar ridge height and the danger of injuring the inferior alveolar nerve. They include, onlay bone grafts ${ }^{4}$, interposition bone gafts ${ }^{5}$, nerve repositioning ${ }^{6}$, distraction osteogenesis ${ }^{7}$, short implants ${ }^{8}$ and the use of metallic mesh to form and retain a particulate graft for vertical ridge augmentation ${ }^{9}$.

Interpositional bone grafts "sandwich-technique" has been used for many years. Several studies showed successful outcomes in vertical height increase ranging from $4-8 \mathrm{~mm}$ and minimal graft resorpion after 1 year follow up ${ }^{5,10}$. Other studies found a median vertical gain of about 6-7 mm using the sandwich osteotomy technique ${ }^{11}$. However, there are some limitations including limitation of augmentation height because of the soft tissue stretching and the precision required to save the mandibular nerve in the horizontal osteotomy ${ }^{12,13}$.

Surgical techniques have been greatly enhanced by the use of computer-aided design/computer-aided manufacturing (CAD/CAM) technology proving to be efficient and highly accurate ${ }^{14,15}$. The computer generated surgical guide templates (SGT) have been used in many applications in the field of oral and maxillofacial surgery like orthognathic surgery ${ }^{16,17}$, jaw reconstruction ${ }^{18}$, TMJ reconstruction and implant surgery ${ }^{19}$. The percision of the rapid prototyped surgical guide templates in accurate fitting have been evaluated and proven to be dependable and reliable in achieving the predicted treatment plan 20

Schneider et al 2009 reviewed the accuracy of computer-guided templates and found that the survival rate of implants placed with computer-guided templates is comparable to conventionally placed implants ranging from $91 \%$ to $100 \%$ after follow up of $12-60$ months ${ }^{21}$. They allow the clinician to safely position the fixtures according to bone volume anatomical structures providing excellent tools for pre-operative implant planning, thus increasing the predictability of esthetic and functional treatment outcomes ${ }^{22-24}$.

Computer generated Surgical Guide Templates (SGT) are the product of Rapid Prototyping concept which is defined as a digital tool that grows parts on layer by layer basis without machining, molding or casting using additive process technique. There are numerous surgical applications for Rapid Prototyping as: Pre-operative visualization and planning, Pre-forming of fixation components, Manufacture of surgical guides and templates, Simulation of surgical procedure, Evaluation of prosthesis fit, Demonstration to patient and Intra-operative guidance Surgeon training ${ }^{25,26}$.

The current study was conducted to evaluate the accuracy of a novel design computer-assisted SGT using rapid prototyping techniques to guide the osteotomy cuts in the sandwich osteotomy technique according to the pre-planned position to aid in preventing injury to the inferior alveolar nerve.

\section{MATERIALS AND METHODS}

A total of eight consecutive patients (6 women and 2 men) with mean age of 44.75 years were selected from the Oral and Maxillofacial Surgery Department, Faculty of Oral and Dental Medicine, Cairo University.

The study protocol was approved by the Research Ethics Committee in Cairo University, Cairo, Egypt prior to data collection and all participants signed an informed consent agreement. No funding or reimbursement was provided to the research or participants.

The following selection criteria were fulfilled: partially edentulous patients with atrophic mandibles in the posterior region, behind the canine region. The starting alveolar bone height above the mandibular canal ranged between 5 and $7 \mathrm{~mm}$ and a transverse width of minimum $4 \mathrm{~mm}$ as measured 


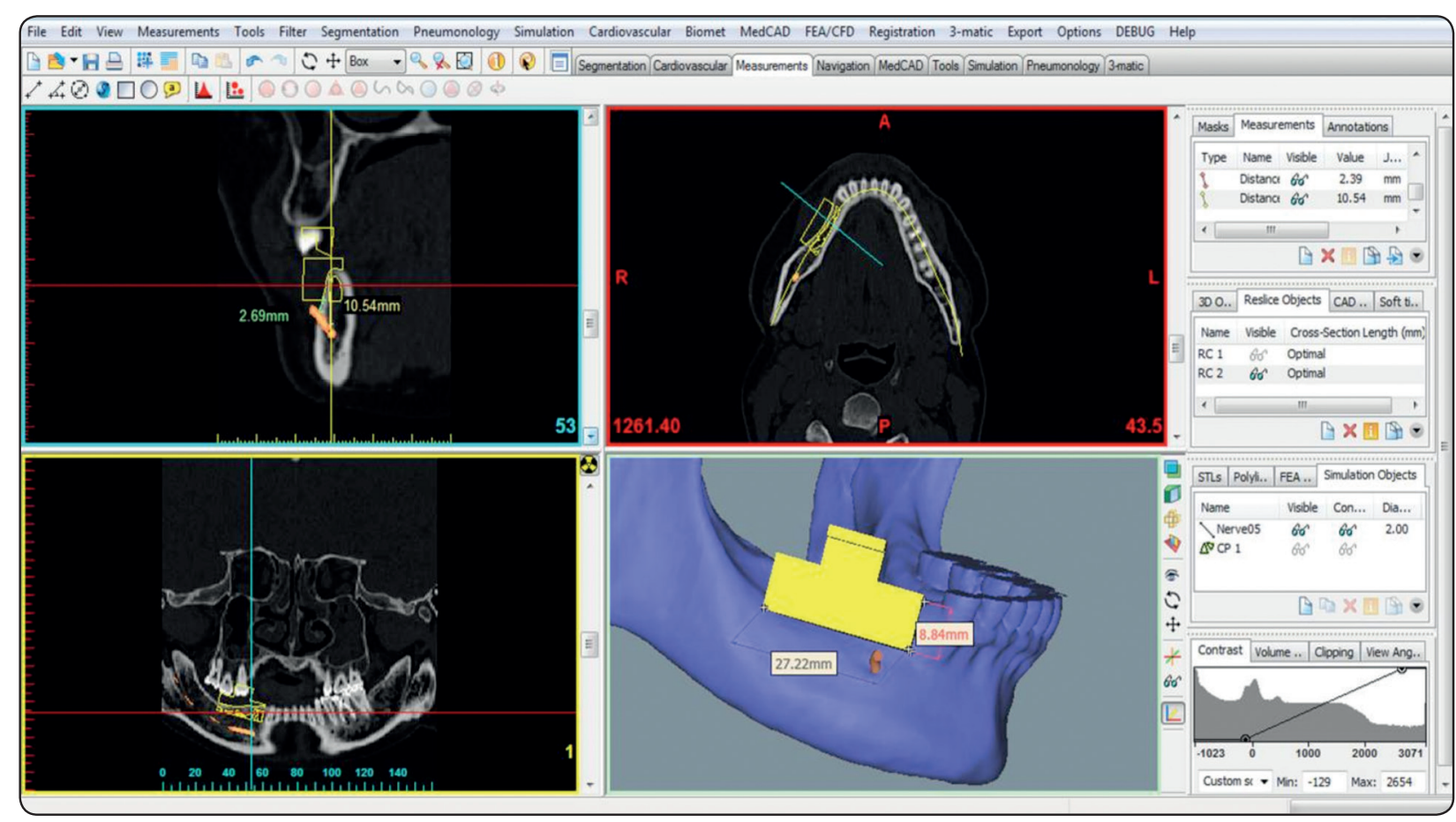

Fig. (1) Showing Virtual SGT design in the coronal, sagittal, axial and 3D views of a 3D modeling software designed individually according to each case.

by Cone-Beam Computed Tomography (CBCT) (I-CAT ${ }^{\circledR} \quad$ Precise $^{\mathrm{TM}}$, manufacturer, I-CAT ${ }^{\circledR}$ technology located in Hatfield, PA). Patients did not have medical or psychological problems that could impede graft or implant success.

\section{Preoperative surgical planning}

Pre-operative CBCT (P0) was performed for each patient, then the DICOM files were imported into a 3D modeling software (mimics 15.0, Materialise) where a Virtual surgical guide template (VSGT) was designed according to each case (Figure 1).

The inferior margin of the template was located at least $2 \mathrm{~mm}$ below the ridge bone and approximately $1.5-2 \mathrm{~mm}$ above the mandibular canal. The inferior margin was designed to have sufficient thickness for the resting of piezo-surgery inserts and chisels. The vertical mesial margin was made $2 \mathrm{~mm}$ distal to the last tooth and the vertical distal margin was made based on the implant-graft treatment planning. The graft thickness was not less than $2 \mathrm{~mm}$ thick.
The VSGT was then exported as STL files to 3D printing machine (InVision Si2, 3D Systems, Rock Hill, SC) using rapid prototyping techniques to fabricate the Final SGT (Figure 2).

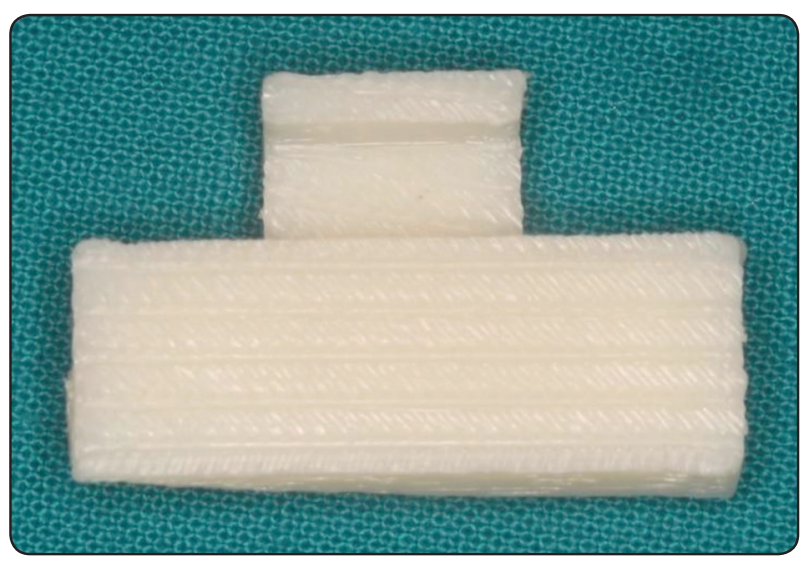

Fig. (2) Final SGT printed using rapid prototyping techniques.

\section{Surgical technique}

The surgical procedure was performed under general anesthesia; patients were scrubbed and draped according to the standard fashion. Local anesthesia 
was induced using articain $4 \%$ and adrenaline $1: 100,000$. A $10-12 \mathrm{~mm}$ incision from the crest of the ridge in the buccal gingiva of the edentulous area was done, and then a mucoperiosteal flap was raised without detaching the lingual mucoperiosteum to expose the buccal cortical bone of the posterior atrophic mandible and the mental nerve.

The SGT was placed on the alveolar bone to fit in the pre-planned position (Figure 3A). Two vertical and one horizontal osteotomies were performed with a piezoelectric surgical device (Piezosurgery, VarioSurg, NSK) along the margins of the template (Figure 3B). A chisel resting on the templates' inferior margin was used to complete the lingual osteotomy. The coronal bone fragment was carefully elevated and stabilized by micro plate (Figure 3D). Bone substitute (TUTOBONE, Tutogen medical $\mathrm{GmbH}$ Industriestraße a. Br. Germany) was placed between the segments. After 4 months postoperatively, the micro plate was removed and dental implants were installed at the grafted site. Immediate post-operative CBCT (P1) and after 4 months (P2) (at the time of surgical reentry just before microplate removal and implant insertion) were taken and compared to the preoperative $\mathrm{CBCT}(\mathrm{P} 0)$.

Linear measurements were taken from $\mathrm{P} 0$ and P1 to verify of the accuracy of the SGT. Paired- $t$ test was used to compare the position of the preplanned and the actual osteotomy cuts. Differences were considered statistically significant when $\mathrm{p} \leq$ 0.05 . Microstat7 for Windows statistical package (Microstat Co.) was used in statistical analysis for this study. Vertical bone gain was assessed by comparing $\mathrm{P} 0$ and $\mathrm{P} 1$. Vertical bone resorption of the augmented ridge was assessed by comparing $\mathrm{P} 1$ and P2 (Table 1).
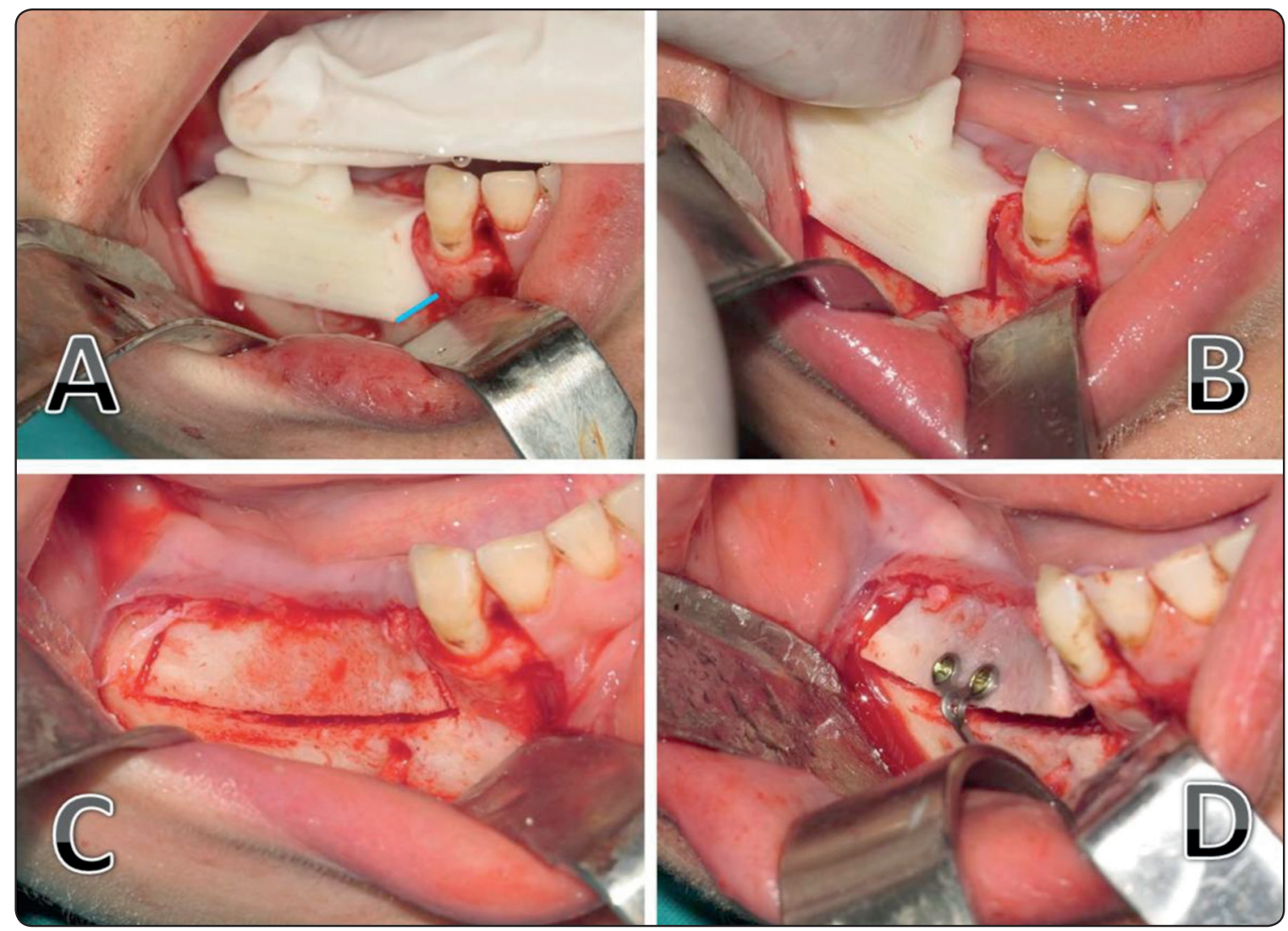

Fig. (3): (A) Fitting of the SGT on the alveolar bone according to the pre-planned position. The blue line shows sufficient thickness at the inferior margins to guide the piezosurgery inserts and chisels in the lingual direction. (B) Osteotomy cuts performed along the margins of the SGT using peizo-surgery. (C) The completed osteotomy cuts, the horizontal osteotomy is accurately placed safely above the inferior alveolar nerve. (D) Fixation of the osteotomized segment with a micro-plate. 
TABLE (1) Showing Patient's Clinical and Radiographic Data:

\begin{tabular}{|c|c|c|c|c|c|c|}
\hline $\begin{array}{c}\text { Patient } \\
\text { No. }\end{array}$ & Sex & Age & $\begin{array}{c}\text { Treated } \\
\text { Site }\end{array}$ & $\begin{array}{c}\text { Starting bone height above the } \\
\text { mandibular canal (P0) }(\mathrm{mm})\end{array}$ & $\begin{array}{c}\text { Vertical bone } \\
\text { gain (P1) (mm) }\end{array}$ & $\begin{array}{c}\text { Vertical bone re- } \\
\text { sorption (P2) (mm) }\end{array}$ \\
\hline$\# 1$ & M & 42 & Right & 5.7 & 5.2 & 0.6 \\
\hline$\# 2$ & F & 55 & Right & 4.8 & 6.2 & 1.9 \\
\hline$\# 3$ & F & 40 & Left & 6.6 & 5.7 & 0.9 \\
\hline$\# 4$ & F & 60 & Right & 6.2 & 6.9 & 1.2 \\
\hline$\# 5$ & F & 32 & Left & 7.6 & 5.9 & 0.7 \\
\hline$\# 6$ & M & 42 & Left & 5.6 & 6.7 & 1.3 \\
\hline$\# 7$ & F & 50 & Left & 7.8 & 4.2 & 0.2 \\
\hline$\# 8$ & F & 37 & Right & 7.2 & 5 & 1.5 \\
\hline
\end{tabular}

\section{RESULTS}

The eight patients showed uneventful healing with no signs of dehiscence during the postoperative course. No signs of inferior alveolar nerve impairment or paraesthesia were reported and the grafted sites showed successful healing and bone gain after 4 month postoperatively (Figure 5). The template showed adequate fitting on the alveolar bone in the pre-planned position.

From the preoperative CBCT, linear measurements were taken starting from the inferior border of the mandible to inferior margin of VSGT at both the mesial and distal ends Figure (4A). From the postoperative CBCT, measurements were taken from the inferior border of the mandible to the actual horizontal osteotomy cut (Figure 4B). The mean values for the linear measurements of the preoperative preplanned and the postoperative actual measurements are shown in (Table 2, Fig. 6). There was no statistically significant difference $(\mathrm{p} \leq 0.05)$ between the preplanned and actual measurements at both mesial and distal ends of the SGT.

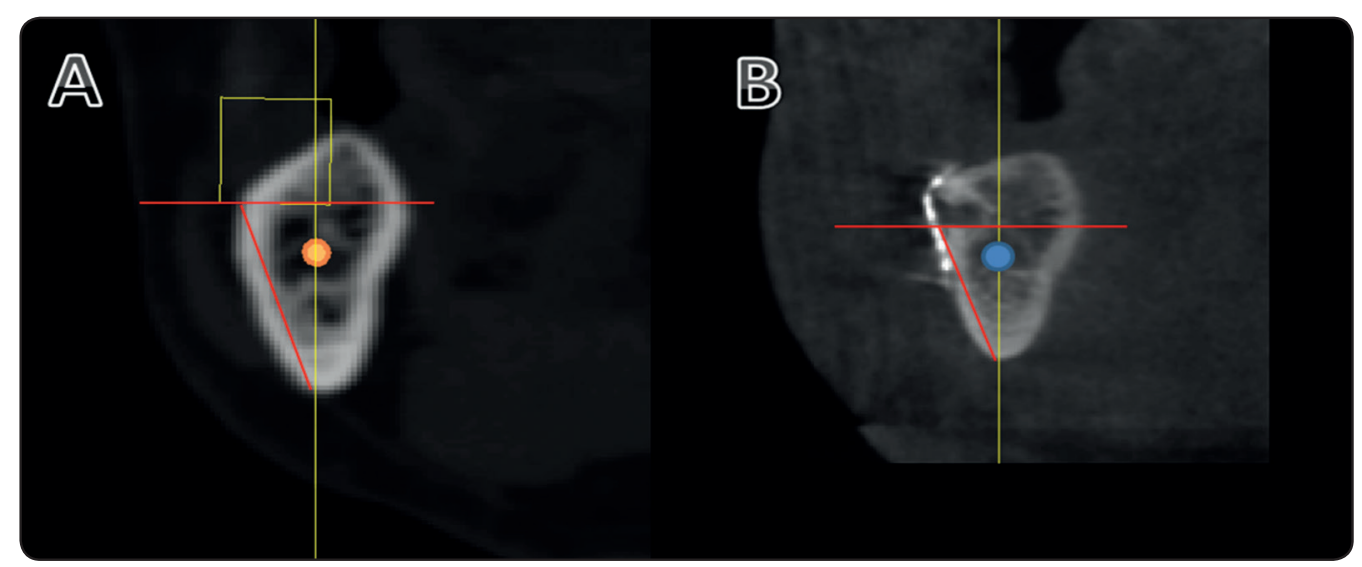

Fig. (4): (A) Linear measurements taken from inferior border of the mandible to the virtual horizontal osteotomy cut. (B) Linear measurements taken from inferior border of the mandible to the actual osteotomy cut. 


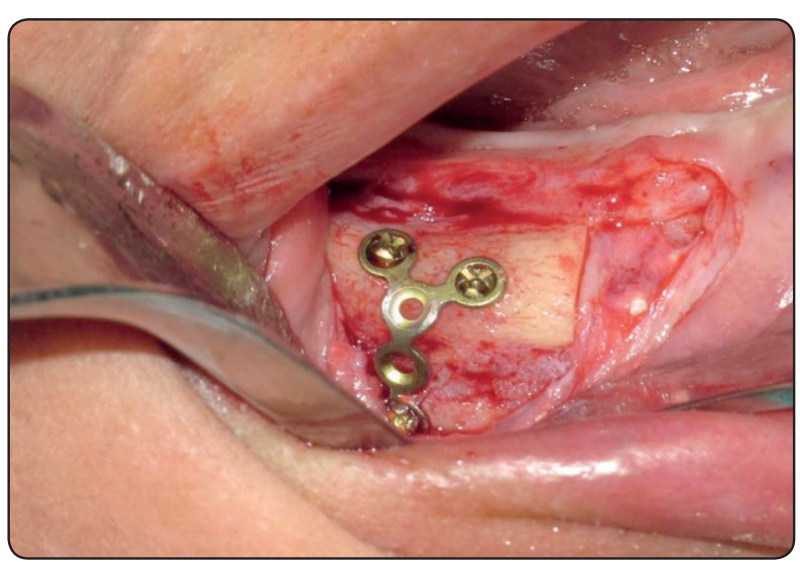

Fig. (5) Successful bone formation at the sandwich osteotomy site.

TABLE (2) Paired " $t$ " test comparing the pre-planned and actual measurements:

\begin{tabular}{|c|c|c|c|c|}
\hline & \multicolumn{2}{|c|}{ Mean \pm St Deviation } & \multirow{2}{*}{ "t" } & \multirow{2}{*}{ Probability } \\
\hline & Preplanned & Actual & & \\
\cline { 1 - 3 } Mesial & $0.30 \pm 19.06$ & $0.56 \pm 18.90$ & 0.942 & NS 0.189 \\
\hline Distal & $0.65 \pm 18.32$ & $1.13 \pm 18.00$ & 1.141 & NS 0.146 \\
\hline
\end{tabular}

The mean value for starting bone height above the mandibular canal was $6.4 \mathrm{~mm}$ (range, $4.8-7.8 \mathrm{~mm}$ ). The mean initial vertical bone gain from P0 to P1 was $5.7 \mathrm{~mm}$ (range, 4.2-6.9 $\mathrm{mm}$ ). The mean bone resorption after four months (P2) was $1.03 \mathrm{~mm}$ (range, $0.20-2.9 \mathrm{~mm}$ ). The mean final vertical augmentation was $4.6 \mathrm{~mm}$ (range, $3.5-5.7 \mathrm{~mm}$ ) (Table 1).

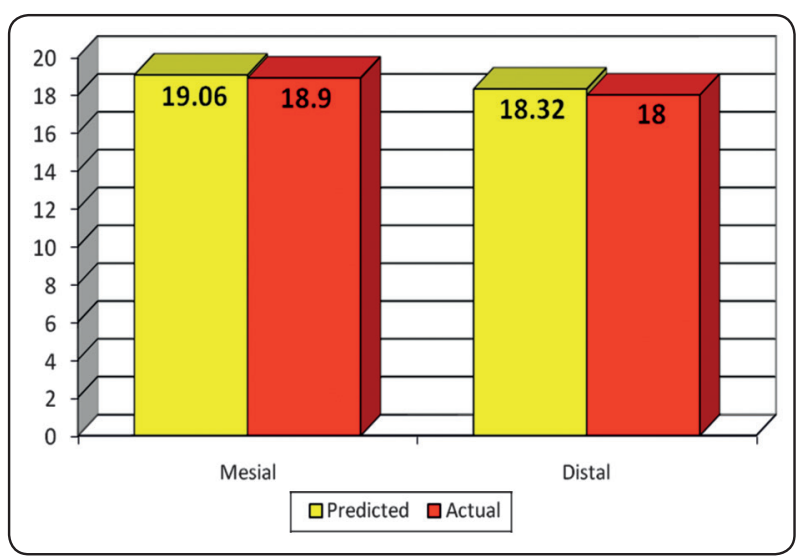

Fig. (6) Graph showing the mean values of the preplanned and actual measurements at the mesial and distal ends of the SGT.

\section{DISCUSSION}

Several techniques have been to advocated to solve defiecient bone height problems in atrophied mandibles to allow for appropriate placement of endossueous implants including onlay bone grafts, alveolar distraction osteogenesis, titanium meshs and transposition of the inferior alveolar nerve.

Numerous studies have shown that sandwich osteotomy is a suitable technique for use as an augmentation procedure for the atrophic mandibular alveolar ridge to provide adequate height and transversal bone augmentation which also helps in the challenging anatomic region of the atrophic posterior ridge ${ }^{12,27}$. However, the most serious difficulty in using the sandwich technique in the posterior mandible is the precision required to save the mandibular nerve in the horizontal osteotomy ${ }^{10}$.

Some studies reported neurosensory dysfunction after interpositional bone grafting ${ }^{28}$. Bormann et al reported sensory mental nerve disturbances in five out of thirteen patients ( $44 \%$ of patients) with recovery after 6 weeks, however they stated that the sensory disturbances was due to flap retraction ${ }^{27}$. Other studies found transient paraesthesia in all eight patients lasting up to 6 weeks ${ }^{29}$. Felice et al showed in a randomized controlled clinical trial with four months follow up that 16 patients $(57 \%)$ had transient postoperative paraesthesia of the inferior alveolar nerve after augmentation procedures using sandwich osteotmy ${ }^{30}$. The current study showed no signs of sensory distrubnaces along the course of the inferior alveolar nerve in all patients during the four months of follow up period.

Three-dimensional (3D) surgical planning and rapid prototyping techniques are becoming increasingly popular with their wide applications in the field of oral and maxillofacial surgery. The diagnostic advances in 3D surgical simulation have enhanced the accuracy of preoperative planning and the surgeon's understanding of the maxillofacial deformity providing better treatment outcomes ${ }^{31}$. 
The accuracy of fitting of computer-genertated surgical guide templates on bone and teeth have been evaluated in several studies ${ }^{32-35}$. Gateno et al assessed the precision of stereolithographic splints fitiing on dentition by comparing them with the conventional acrylic splints. Based on the quantity of air space between the teeth and the 2 types of splints studied, they have shown that stereolithographic surgical splints fit the same as conventional surgical splints ${ }^{20}$.

Other studies evaluated the efficiency of preoperative virtual treatment planning and computer generated splints in orthognathic surgery and concluded that the 3D splints can incorporate more accurately the surgical treatment plan, especially in complex cases ${ }^{17,31,32}$. Surgical guiding templates have also shown high degrees of accuracy in reconstruction cases after tumor resection and proved that bone segments of the grafts and mandibular remnants could be positioned accurately according to the preoperative simulation ${ }^{35,36}$.

The newly designed SGT showed adequte fitting on the alveolar bone in the pre-planned position and the osteotomy cuts were easily placed at the surgical site. The thickness of the inferior margin in the SGT guided the direction of the piezo inserts and allowed for resting of the chisels to complete the osteotomy thus providing a cutting control in the lingual direction. The preoperative virtual treatment planning of the SGT aided in determining the desired length of the bone segment to to be elevated accordingly to accommodate for implant placement after 4 months.

There was no statistically significant difference $(\mathrm{p} \leq 0.05)$ between the virtual and actual positions of the osteotomy cuts guided by the SGT which correlates with the proper fitting of the template during the procedure thus providing an efficient and reliable technique to obtain safe and precise osteotomies. Increasing the sample size for futher verification of the above results is to be considered.
The application of the novel computer-generated SGT showed significant amount of accuracy in transferring the preoperative treartment plan and provided a less technique sensitive procedure helping to eliminate the difficult aspect of using the sandwich technique which is the precision required to save the mandibular nerve. CAD/CAM technology provided enhanced visualization, better treatment planning, decreased intra-operative time and more predictable results.

\section{REFERENCES}

1. Devlin H, Ferguson MW. Alveolar ridge resorption and mandibular atrophy. A review of the role of local and systemic factors. British dental journal. 1991;170:101-104.

2. Haraldson T, Karlsson U, Carlsson GE. Bite force and oral function in complete denture wearers. Journal of oral rehabilitation. 1979;6:41-48.

3. Haraldson T, Carlsson GE. Bite force and oral function in patients with osseointegrated oral implants. Scandinavian journal of dental research. 1977;85:200-208.

4. Palmer P, Palmer R. Dental implants. 8. Implant surgery to overcome anatomical difficulties. British dental journal. 1999;187:532-540.

5. Bianchi A, Felice P, Lizio G, Marchetti C. Alveolar distraction osteogenesis versus inlay bone grafting in posterior mandibular atrophy: a prospective study. Oral surgery, oral medicine, oral pathology, oral radiology, and endodontics. 2008;105:282-292.

6. Ferrigno N, Laureti M, Fanali S. Inferior alveolar nerve transposition in conjunction with implant placement. The International journal of oral \& maxillofacial implants. 2005;20:610-620.

7. Chiapasco M, Romeo E, Casentini P, Rimondini L. Alveolar distraction osteogenesis vs. vertical guided bone regeneration for the correction of vertically deficient edentulous ridges: a 1-3-year prospective study on humans. Clinical oral implants research. 2004;15:82-95.

8. das Neves FD, Fones D, Bernardes SR, do Prado CJ, Neto AJ. Short implants--an analysis of longitudinal studies. The International journal of oral \& maxillofacial implants. 2006; 21:86-93. 
9. Fontana F, Santoro F, Maiorana C, Iezzi G, Piattelli A, Simion M. Clinical and histologic evaluation of allogeneic bone matrix versus autogenous bone chips associated with titaniumreinforced e-PTFE membrane for vertical ridge augmentation: a prospective pilot study. The International journal of oral \& maxillofacial implants. 2008;23:1003-1012.

10. Bormann KH, Suarez-Cunqueiro MM, von See C, et al. Forty sandwich osteotomies in atrophic mandibles: a retrospective study. Journal of oral and maxillofacial surgery : official journal of the American Association of Oral and Maxillofacial Surgeons. 2011;69:1562-1570.

11. Marchetti C, Trasarti S, Corinaldesi G, Felice P. Interpositional bone grafts in the posterior mandibular region: a report on six patients. The International journal of periodontics \& restorative dentistry. 2007;27:547-555.

12. Block MS, Haggerty CJ. Interpositional osteotomy for posterior mandible ridge augmentation. Journal of oral and maxillofacial surgery : official journal of the American Association of Oral and Maxillofacial Surgeons. 2009; 67:3139.

13. Felice P, Pellegrino G, Checchi L, Pistilli R, Esposito M. Vertical augmentation with interpositional blocks of anorganic bovine bone vs. 7-mm-long implants in posterior mandibles: 1-year results of a randomized clinical trial. Clinical oral implants research. 2010;21:1394-1403.

14. Carls FR, Schuknecht B, Sailer HF. Value of three-dimensional computed tomography in craniomaxillofacial surgery. J Craniofac Surg. 1994;5:282-288.

15. Fuhrmann RA, Frohberg U, Diedrich PR. Treatment prediction with three-dimensional computer tomographic skull models. Am J Orthod Dentofacial Orthop. 1994; 106:156-160.

16. Metzger MC, Hohlweg-Majert B, Schwarz U, Teschner M, Hammer B, Schmelzeisen R. Manufacturing splints for orthognathic surgery using a three-dimensional printer. Oral Surg Oral Med Oral Pathol Oral Radiol Endod. 2008; 105:e1-7.

17. Shehab MF, Barakat AA, AbdElghany K, Mostafa Y, Baur DA. A novel design of a computer-generated splint for vertical repositioning of the maxilla after Le Fort I osteotomy. Oral surgery, oral medicine, oral pathology and oral radiology. 2013;115:e16-25.

18. Hou JS, Chen M, Pan CB, et al. Application of CAD/ CAM-assisted technique with surgical treatment in reconstruction of the mandible. Journal of cranio-maxillo-facial surgery : official publication of the European Association for Cranio-Maxillo-Facial Surgery. 2012;40:e432-437.

19. Orentlicher G, Abboud M. Guided surgery for implant therapy. Oral and maxillofacial surgery clinics of North America. 2011;23:239-256, v-vi.

20. Gateno J, Xia J, Teichgraeber JF, Rosen A, Hultgren B, Vadnais $\mathrm{T}$. The precision of computer-generated surgical splints. Journal of oral and maxillofacial surgery : official journal of the American Association of Oral and Maxillofacial Surgeons. 2003;61:814-817.

21. Schneider D, Marquardt P, Zwahlen M, Jung RE. A systematic review on the accuracy and the clinical outcome of computer-guided template-based implant dentistry. Clinical oral implants research. 2009;20 Suppl 4:73-86.

22. Katsoulis J, Pazera P, Mericske-Stern R. Prosthetically Driven, Computer-Guided Implant Planning for the Edentulous Maxilla: A Model Study. Joannis Katsoulis; Pawel Pazera; Regina Mericske-Stern. 2009;11:238-245.

23. Xia JJ, Gateno J, Teichgraeber JF. Three-dimensional computer-aided surgical simulation for maxillofacial surgery. Atlas Oral Maxillofac Surg Clin North Am. 2005; 13:25-39.

24. Xia J, Ip HH, Samman N, et al. Computer-assisted threedimensional surgical planning and simulation: 3D virtual osteotomy. International journal of oral and maxillofacial surgery. 2000;29:11-17.

25. Berry E, Brown JM, Connell M, et al. Preliminary experience with medical applications of rapid prototyping by selective laser sintering. Medical engineering \& physics. 1997;19:90-96.

26. Aung SC, Tan BK, Foo CL, Lee ST. Selective laser sintering: application of a rapid prototyping method in craniomaxillofacial reconstructive surgery. Annals of the Academy of Medicine, Singapore. 1999;28:739-743.

27. Bormann KH, Suarez-Cunqueiro MM, von See C, Kokemuller H, Schumann P, Gellrich NC. Sandwich osteotomy for vertical and transversal augmentation of the posterior mandible. International journal of oral and maxillofacial surgery. 2010;39:554-560.

28. Frost DE, Gregg JM, Terry BC, Fonseca RJ. Mandibular interpositional and onlay bone grafting for treatment of mandibular bony deficiency in the edentulous patient. Journal of oral and maxillofacial surgery : official journal of the American Association of Oral and Maxillofacial Surgeons. 1982;40:353-360. 
29. Jensen OT. Alveolar segmental "sandwich" osteotomies for posterior edentulous mandibular sites for dental implants. Journal of oral and maxillofacial surgery : official journal of the American Association of Oral and Maxillofacial Surgeons. 2006;64:471-475.

30. Felice P, Cannizzaro G, Checchi V, et al. Vertical bone augmentation versus 7-mm-long implants in posterior atrophic mandibles. Results of a randomised controlled clinical trial of up to 4 months after loading. European journal of oral implantology. 2009;2:7-20.

31. Metzger MC, Hohlweg-Majert B, Schon R, et al. Verification of clinical precision after computer-aided reconstruction in craniomaxillofacial surgery. Oral surgery, oral medicine, oral pathology, oral radiology, and endodontics. 2007;104:e1-10.

32. Swennen GR, Mollemans W, Schutyser F. Three-dimensional treatment planning of orthognathic surgery in the era of virtual imaging. Journal of oral and maxillofacial surgery : official journal of the American Association of Oral and Maxillofacial Surgeons. 2009;67:2080-2092.

33. Polley JW, Figueroa AA. Orthognathic positioning system: intraoperative system to transfer virtual surgical plan to operating field during orthognathic surgery. Journal of oral and maxillofacial surgery : official journal of the American Association of Oral and Maxillofacial Surgeons. 2013;71:911-920.

34. Cassetta M, Giansanti M, Di Mambro A, Calasso S, Barbato E. Accuracy of two stereolithographic surgical templates: a retrospective study. Clinical implant dentistry and related research. 2013;15:448-459.

35. Zheng GS, Su YX, Liao GQ, Liu HC, Zhang SE, Liang LZ. Mandibular reconstruction assisted by preoperative simulation and accurate transferring templates: preliminary report of clinical application. Journal of oral and maxillofacial surgery : official journal of the American Association of Oral and Maxillofacial Surgeons. 2013; 71:1613-1618.

36. Zheng GS, Su YX, Liao GQ, et al. Mandible reconstruction assisted by preoperative simulation and transferring templates: cadaveric study of accuracy. Journal of oral and maxillofacial surgery: official journal of the American Association of Oral and Maxillofacial Surgeons. 2012;70:1480-1485. 